\title{
Comparative and informative characteristic of the legal regulation of the blockchain and cryptocurrency: state and prospects
}

Balian Anush, doctor of economic sciences, professor, Vice-president of NAAS, National Academy of Agrarian Sciences, 9, Omelianovych-Pavlenko Str., Kyiv, 01010, Ukraine, https://orcid.org/0000-0003-21902022

Gryshova Inna, doctor of economic sciences, professor, National Scientific Center «Institute of Agrarian Economy, Heroiv Oborony str. 10, 03127 Kyiv, Ukraine, orcid.org/0000-0001-6276-7619

Diachenko Oleksii Petrovich, doctor of Economics, associate Professor Jiangsu Normal University, 101 Shanghai Rd, Tongshan Qu, Xuzhou Shi, 221100, Jiangsu Sheng, China ORCID ID: 0000-0001-9670-2266

Batrakova Tetyana, PhD associate Professor, Zaporizhya National University, Ukraine, ORCID 0000-00025710-9416

\begin{abstract}
The authors analyzed the market of cryptocurrency goods, considered the essence of cryptocurrency and proposed the definition of their legal status, studied the experience of some jurisdictions regarding the possibilities and threats of the use and regulation of cryptocurrency.

In the process of analyzing the experience of regulating cryptocurrency, we have found similar and distinctive features in some jurisdictions. First, each country, in view of the great potential of the blockchain technology, is trying in one way or another to create a favorable climate for its development. Secondly, the use of cryptocurrency goods is rapidly developing, and their impact on economic processes, both at the international and national levels is increasing, while states are faced with the problem of adapting their tax legislation to the current challenges of the digital economy, since the definition of the status of cryptocurrency does not directly lead to lack of funds to the state budget from operations with these assets. Thirdly, today there are more than 2,000 cryptocurrency is traded through various trading platforms - stock exchanges and can be used to launder proceeds from crime. Thus, it is necessary to develop common standards for the regulation of cryptocurrency and the requirements for such crypto exchange counterparts, through the licensing of operations with cryptocurrencies. At the same time, the important question is what government bodies should exercise such control.
\end{abstract}

Keywords: technology blockchain, cryptocurrency, virtual currency, legal regulation of cryptocurrencies, state functions, cryptocurrencies taxation.

Received: $14.12 .2020 \quad$ Accepted: 23.01.2021 $\quad$ Published: 03.02.2021

\section{Introduction}

All countries of the world have, to a greater or lesser extent, faced with the problem of determining the legal status of cryptocurrency, the establishment of their place in the system of settlements among the participants in economic turnover, the problem of taxation and licensing of transactions with cryptocurrencies, the definition of state bodies that must monitor cryptocurrencies in order to prevent their use them in illegal activities and money laundering.

Given the novelty of the financial instrument of the cryptocurrency, we were interested in the problem of its legal status in the world. At the same time, the views of prominent scholars on this issue are quite interesting and controversial. It should be noted that many works by scientists, (see e.g. Kshemkalyani A 2008), are devoted to the purely technical aspect of the use of the blockchain technology. Another (Barrdear J 2016; MacDonald T.J 2016) devoted their attention to the comparison of the blockchain technology in the context of its interaction with the banking system.

It should also be noted that, given the novelty of the instrument and its multifunctionality, there is no unity in the definition of the concept of "cryptocurrency". Thus, in particular, M. Abramovich (2015) under cryptocurrencies understands "the kind of digital currency issue, which account requires the use of asymmetric encryption and cryptographic methods of protection". In what, according to David Mills (2016) and Dong He (2016), the legal nature of most of the digital assets built on the blockchain technology is still unclear (Gryshova, I.I., Mityay, O.V., Kuzhel, V.V.. (2015)

Quite controversial thoughts on the cryptocurrency are expressed by some Nobel laureates. Thus, in particular, Robert Schiller (2018) noted that Bitcoin is the best example of a soap bubble. However, another well-known American economist and Nobel Prize laureate Milton Friedman (1999), before the cryptocurrency exist, said: "The only thing that is missing, but what will soon be - is a reliable electronic 
money - a method by which you can buy something on the Internet or transfer funds from user A to user $B$, and these users may not know each other at all". Also supports the use of distributed registry technology, the Nobel Prize winner Angus Ditton (2015), which states that "the problem of remittances lies in their high cost and inefficiency. In his view, thanks to the speed and low cost of transactions in the bitcoin network of Third World countries, they can get a great deal of money from cross-border money transfers".

Despite the large number of discussions about the blockchain technology, we did not find answers to the question of a single legal definition and legal status of cryptocurrency, their regulation at the state and international levels. In particular, there is a large number of risks associated with the operation of buying, selling, exchanging and converting into cryptocurrencies, there remains the risk of possible misuse of such payment systems. (Dr. Tetiana Tielkiniena, Gryshova Inna, Shabatura Tatyana, Nehodenko Viktoriia, Didur Hanna, Shevchenko Alisa, 2020)

\section{Materials and methods of research}

The task of determining the essence of blockchain technology and cryptocurrencies was investigated using the historical method in order to assess the state of modern legal regulation of these technologies.

The dialectical method has allowed uncovering the unity and contradictory nature of the approaches of different legal jurisdictions to determine the status of cryptocurrency, their place in the national legal system, and the possibility of taxing operations related to their application. Thanks to the method of analysis and synthesis, the essence of the concept of "money" and its comparison with the concepts of "cryptocurrency", "virtual currency", "digital currency"

System analysis, which is based on the principles of unity of logical and historical, made it possible to conclude that the legal regulation of states in the field of cryptocurrencies is carried out in four main areas: the definition of the legal status of cryptocurrencies, taxation of operations with crypto currencies, licensing of activities of the company that carry out activities in the field exchange of crypto-currency, counteraction to laundering of proceeds from crime through the use of cryptocurrencies.( Gryshova, I.; Shabatura, T.; Girdzijauskas, S.; Streimikiene, D.; Ciegis, R.; Griesiene, I,2019)

The formal legal method of the investigation made it possible to analyze the peculiarities of the legal regulation of phenomena associated with the blockchain technology in different countries of the world.

\section{Results and discussions}

Globalization processes, in their positive and negative attitudes, have largely influenced a number of global, geopolitical, regional and state financial crises, which in turn led representatives of different social classes to seek alternatives to store and augmenting funds (Barrdear J. 2016). At the same time, more and more individuals and entrepreneurs in different countries recognize the effectiveness of using cryptocurrency. Indicative is the fact that in many developing countries, cryptocurrencies are in great demand. Thus, in spite of the lack of official legalization in Ukraine, at the beginning of 2017, this country was recognized as one of the world leaders using cryptocurrency as a whole. A similar situation is observed in Argentina. Financial instability, significant currency fluctuations, capital flight constraints, and national currency inflation in the country led to the spread of cryptocurrencies.

So what is a blockchain? Under the blockchain is a distributed database (register), that is, one that is stored and synchronized, in full or in part (at a minimum, record a large number of recent transactions) for each member of this network. The peculiarity of this technology is that the information stored is at the same time in all participants in the system, while none of them controls neither all information nor any critical part. Thus, the security of the whole blockchain system before the hacker attacks from the outside, since the disconnection of one or more participants does not eliminate the whole system as a whole. Base storage means participation in the system and, accordingly, the presence of a unique key necessary for addressing transactions (participant's address or "purse"). The presence or absence of any other information about the user in the database does not affect the operation of the system - so blockchain can be anonymous, that is, only include addresses of participants (their "wallets").

Another important issue to be addressed for the practical application of this technology is the problem of information security, which was solved by combining block design and cryptographic protection. In this case, the use of cryptographic protection became possible due to the "defeat" of the state to restrict the use of cryptography in the scientific and technical life of society, in the so-called "crypt-wars" that took place in the United States in the early 1990's, which in turn led to a general weakening of state regulation in the field of export of technologies that used cryptography.

The most commonly used implementation of the blockchain technology is the Bitcoin cryptographic database, which at the end of October 2018 amounted to 220.27 GB and is steadily increasing. Thus, decentralized databases are economically unprofitable to store bulky databases or files. Distributed 
registry is not effective as a "cloud" data warehouse, but as a consistent and consistent story of transactions in the network, where none of the participants trusts others. Given that Bitcoin was the first protocol created on the basis of the blockchain technology, it is often used in popular literature and mass media as synonyms. At the same time, according to statistics, over the past few years, the capitalization of the cryptocurrency market has grown almost 12 times from 17.7 billion dollars. US at the beginning of 2017 to 208.9 billion dollars. The US at the end of October 2018, with the number of cryptocurrencies, over the same period increased in 3,24 times from 640 to 2076.

Among the most popular cryptocurrencies in the world, the leaders in the growth are Bitcoin, Ethereum, Litecoin, NEM, Bitcoin Cash, DASH, Monero and IOTA - they own 80\% of total capitalization (see Table 1). The price of the first cryptocurrecy bitcoin reached a mark of 6483 dollars. for 1 BTC, at which the historic maximum reached 19,380 dollars. USA.

Table 1. The capitalization of the Top 10 cryptocurrencies is on the 27 th of October 2018

\begin{tabular}{|l|l|}
\hline Name of the cryptocurrency & Capitalization, USD USA \\
\hline Bitcoin & 112457436177 \\
\hline Ethereum & 20933209024 \\
\hline Ripple & 18352116765 \\
\hline Bitcoin Cash & 7620317172 \\
\hline EOS & 4867115362 \\
\hline Stellar & 4410550482 \\
\hline Litecoin & 3062328810 \\
\hline Tether & 1905591838 \\
\hline Cardano & 1897936910 \\
\hline Monero & 1719714176 \\
\hline
\end{tabular}

In the analysis of analytical studies conducted by specialists in the field of finance and legal regulation, despite the minimal influence of the state on the regulation of such social relations (Vasylchak, KunytskaIlyash and Dubyna 2017), there are a number of problems that need to be addressed, namely:

1. Blockchain is a new technology, which is designed to solve some problems technologically, not legally, such as the problem of double debiting, execution of smart contracts, etc. Such actions become impossible due to asymmetric encryption and block chains. It is profitable economically, because there is a significant reduction in costs. However, with this, blockchain technology is not as flexible as the legal system, and therefore the interaction of these two systems is also required in solving the "border issues" on which the blockchain interacts with objects of the real world.

2. When using blockchain, a cross-border exchange of data is possible, affecting another urgent problem extra-territoriality (see Case US v. LibertyReserve S.A.).

3. So far, there are no recognized practices of regulation of blockchain and cryptocurrency in the world in view of the need for their comprehensive regulation of legal norms in various areas of law (civil, economic, monetary, financial, securities regulation, etc.).

In view of the above, there is a need for the following: the definition of the legal status of cryptocurrencies; the establishment of a place of cryptocurrency in the system of settlements among the participants in economic turnover, the need for taxation of transactions associated with cryptocurrency; the problem of licensing operations with cryptocurrencies and the definition of state bodies that must control cryptocurrencies in order to prevent their use in illegal activities, in particular terrorist financing, and laundering of proceeds from crime.

For today, the discussion among scholars about the legal nature of cryptocurrencies is not overlooked: they are defined both as money and as a means of exchange or calculation, different from money, and as money surrogates, and even as commodities (Mils 2016; Dong He 2016). It is therefore advisable to consider the analysis of the definition of money.

American Dictionary The Black's Law Dictionary (Bryan A. Garner 2009) provides several definitions of money, including: government-approved exchange tools, or assets that can easily be converted into cash. The Cambridge dictionary defines money as: coins or banknotes (special pieces of paper) that are used to purchase things or the number that people have (2018). The modern explanatory dictionary of the Ukrainian language defines money as metal and paper marks, which is a measure of value during the purchase or sale (Dubicinsky 2008).

Similar views on the definition of the essence of money are also noted in doctrinal works, so according to the theory of K. Marx, they can distinguish five functions of money: a measure of value; exchange 
(turnover); means of accumulation (the formation of wealth); means of payment; world money (Marx 1969).

So the question arises whether decentralized cryptocurrencies are money? If we analyze the functions of cryptocurrency in terms of the above criteria, then we can conclude that cryptocurrencies have the same functions as ordinary money. They can be used as a universal means of exchange and payment. At the same time, today more and more participants in economic turnover use digital currency. Only in Ukraine over the past few years about 20 companies have started to work with cryptocurrencies (Vasylchak, Kunytska-Ilyash and Dubyna 2017), and since the fall of 2017, the first transaction was signed in Ukraine to purchase real estate for cryptocurrency (Karpenko 2017).

Like traditional money, cryptocurrencies can act as a means of accumulation, envisaging the possibility of their real use in the future. Despite the fact that the high volatility of cryptocurrencies makes them quite risky means of accumulation, but in principle this possibility is not excluded.

If you evaluate a cryptocurrency in terms of value, then it primarily consists in determining the value of all goods by setting prices for them in certain monetary units. In this case, the value expressed in money is the price, and when the price is established, the ratio of the values of various products (expressed in identical units) is established, which can result in such goods being comparable and exchanged. Given this definition of the measure of value, one can safely assert that the cost of any goods, services, or works can be expressed in cryptocurrency. Given the above, the question arises as to how the definition of the status of cryptocurrency is in a particular of a different country? It should be noted that neither in scientific circles nor at the level of governments of different states there is unity as to which category cryptocurrency should be considered.

Representatives of the Bank of England in their report used the term "digital currency," while noting that it is not very accurate and may cause some misunderstanding (Barrdear 2016). The Department of the Treasury of Financial Crime in the US network has identified virtual currency as a currency exchange tool that acts as a currency in some environments, but has no generally accepted signs of the true currency. In particular, the virtual currency does not have the status of legal means of payment in any jurisdiction of the world. The National Bank of Ukraine, in a joint statement of financial regulators on the status of cryptocurrencies in Ukraine, noted that the complex legal nature of cryptocurrencies does not allow them to be recognized either by money, currency or payment instrument of another country, or currency value, or electronic money, or securities, or monetary a surrogate (NBU 2014). At the same time, participants in the G20 summit, held in Buenos Aires on March 19-20, 2018, generally refused to use the term cryptocurrency, replacing it with crypto-assets, which explicitly emphasized: there are no cryptographic assets key attributes of sovereign currencies.

At the same time, Britain is one of the leaders in cryptocurrency integration, as well as one of the most favorable and convenient jurisdictions for conducting cryptocurrency business. Moreover, the state provides support for startups related to the digital currency. As noted above, the Bank of England recognized cryptocurrencies as digital money. However, the government has not made a final position on the legal regulation of their activities. Cryptocurrencies was classified as "private money". In essence, cryptocurrency is in the gray zone (legal vacuum). However, the Treasury of the United Kingdom in 2014 initiated a request for information on electronic money, the purpose of which was to obtain information from the government on the barriers for using cryptocurrencies by business entities and their prospects for future use. Having received more than 120 responses, the Government agreed with the views of the Central Bank and the majority of the participants in this dialogue that the use of digital currencies represents minimal risks for financial stability and the UK monetary system.

It should also be noted that several working groups and initiatives on the status of cryptocurrency have been established in the United Kingdom. In particular, in February 2016, the working group on the virtual currencies of the Commonwealth in the report on the legal status of the digital currency and the regulation of operations with it, noted that "virtual currencies" are defined as "digital representation of value, which can be traded in digital terms and function as a means exchange, unit of account and / or stored value, but has no legitimate payment status in any jurisdiction" (The commonwealth 2015).

In 2014, the Financial Conduct Authority of the United Kingdom (FCA) confirmed that Bitcoin is not a currency and no money, so cryptocurrency cannot in any way be regulated by UK financial legislation. In this case, in the UK and to this day, cryptocurrency is considered a unique combination of digits obtained as a result of complex mathematical calculations and algorithms (Barrdear 2016). As of April 2018, the FCA stated that, along with the Bank of England and the British Treasury, they are working on a document on cryptocurrency. At the same time, the Office noted that cryptocurrency is a region of increased interest for markets and regulators around the world.

The determining factor is the fact that in April 2016, the management of the first cryptocurrency company Circle was registered. Thanks to this, she agreed to cooperate with the Barclays Bank, which 
was essentially the first precedent for the joint work of a large banking institution and a cryptocurrency company. In the same month, the Treasury of Great Britain published a plan to combat the legalization (laundering) of proceeds from crime. In this document, the Treasury proposed the application of legislation in the field of legalization (laundering) of proceeds from crime, in relation to exchanges and other crypto-exchange companies that carry out currency exchanges (Action plan 2016).

It was also important to resolve the issue of taxation of transactions related to cryptocurrencies. In 2014, the Tax and Customs Office issued an appropriate document stating that the operations of mining and crypto exchange on any other currency are not subject to value added tax. However, if goods or services have been sold for cryptocurrencies, then such transactions are subject to VAT. In this case, the value of goods or services subject to VAT, must correspond to the value of cryptocurrency in pounds sterling at the time of such an operation. In addition, this document noted that the income of business entities may be taxed on capital gains, as well as corporate and income tax.

Also, it should be noted that the European Union is actively conducting research on issues related to cryptocurrencies. However, despite numerous statements and reports from various government organizations, including the European Central Bank, the European Commission, the European Parliament, none of the EU regulatory authorities has adopted specific regulations on cryptocurrencyy activities. At the same time, in early 2016, the European Commission announced its intentions for tighter regulation of crypto-exchange platforms and companies representing cryptocurrency wallets. Emphasizing, therefore, that such companies should apply the "know-your-customer" rule introduced by the 4th Money Laundering Directive and exchange transactions involving exchange of cryptocurrencies in other currencies, including fiat money (European Commission 2016). In the framework of this plan, in July of that year, the European Commission proposed to adopt a directive obliging cryptocurrency exchanges and cryptocurrency vendors to comply with the requirements of the Directive on the prevention of the use of the financial system for the purpose of money laundering and terrorist financing. It was proposed to introduce compulsory registration or licensing of cryptocurrency exchanges that exchange cryptocurrency on fiat money and vice versa, as well as cryptocurrency purse providers. At the same time, instead of the term "cryptocurrency", the term "virtual currency" was proposed and its definition as a means of payment. In addition, the draft Directive provided for the creation of a central database of information on users of digital currencies.

As a consequence of such proposals in October 2016, the ECB noted that:

- cryptocurrency exchanges that exchange virtual currencies on fiat money, as well as providers of cryptocurrency purses are subject to mandatory registration and licensing;

- noted that virtual currencies are not money in terms of EU legal acts;

- pointed to the imperfection of the definition of the term "cryptocurrency" as a virtual currency and the means of payment, according to the regulator, cryptocurrency - a means of exchange;

- noted that widespread use of cryptocurrencies could undermine the ability of central banks to adequately control the circulation of money in the economy (ECB 2016).

The question of taxation of cryptocurrency transactions was partially settled in the case of Hedqvist $\mathrm{v}$. Sweden, Case C-264/14 of the European Court, in which the court noted that transactions with Bitcoin and other virtual currencies in the European Union should not be subject to value added tax. Such a court decision equates virtual currencies to traditional currencies in terms of taxation. According to the court ruling, operations on exchanging traditional currencies at Bitcoin should be free of value added tax, as the EU rules prohibit the collection of such a tax on currency exchange transactions, banknotes and coins. The judgment of the European Court also removes the question of which types of assets should be assigned a virtual currency, at least as regards the taxation of transactions involving cryptocurrencies (see Case Hedqvist v. Sweden 2015).

The experience of the United States of America in relation to the issue is also of interest. The specificity of the United States is that, firstly, it is an Anglo-Saxon family system and in the territory of this state plays a significant role in the judicial precedent, while the second legal system of this state consists of two levels: federal and state law. Thus, different authorities, differently approach to the definition of the legal statute of cryptocurrencies.

As noted by the specifics of the legal system of the United States, it is two-level. At the federal level, the Internal Revenue Service (hereinafter - the Internal Revenue Service), the FinCEN Department of Securities, the Securities and Exchange Commission (SEC), and the Commodity Futures Trading Commission (CFTC) are involved in regulating cryptocurrencies transactions.

In 2013, FinCEN has identified virtual currency as a currency exchange medium that acts as a currency in some environments, but does not have commonly accepted features of the real currency. In particular, the virtual currency does not have the status of legal means of payment in any jurisdiction of the world. The regulator also determined that companies that provide services for the transfer, sale or exchange of the 
digital currency should be registered as Money Transmitters (Action plan 2016). Such companies should operate directly within the framework of the current legislation on the prevention of money laundering and money laundering, and apply the "know-your-customer" rule, first of all to identify the identity of the user, and must keep a register of such users for carrying out further operations with them.

Later, in 2014, FinCEN issued two more documents on companies that deal with cryptocurrencies and cryptocurrency software development companies. In these two documents, the regulator has determined that such companies are not subject to appropriate registration.

Despite the definition by the Department of Treasury of Financial Crimes - the virtual currency as a means of exchange, another regulatory body - the Trade Commission on Commodity Futures (CFTC) has equated the cryptic currency with goods, thus Bitcoin and other cryptocurrencies must be regulated by the Law on Commodity Exchange. In December 2017, this commission officially allowed the start of trading in futures on Bitcoin. Christopher Giancarlo, chairman of the commission, noticed that Bitcoin is a virtual currency, a commodity with which the commission has never been faced yet.

Another regulator The Securities and Exchange Commission (SEC) regards cryptocurrency as a digital value embodiment that is distributed in a digital form and can be used as a means of accounting, exchange, or accumulation and is not controlled by any central bank. However, in 2017, the Commission stated that tokens could be recognized as securities in the presence of appropriate conditions (for example, the provision of voting rights, shares in the company, promise of profit, etc.). Howey Test, Family Resemblance Test, Capital Risk Test, and some other, additional tests (European Commission 2016) are used to determine whether a token is a security (so-called Equity Tokens). In this case, the regulator stated that such currencies as Bitcoin and Etherium are not securities, but are commodities and subject to CFTC regulation.

There is no unity in determining the status of cryptocurrency and among representatives of the judicial branch, because, as noted above, an important role is played by the precedent in the United States. In August 2013, the judge of the District Court of the East Texas County, Eimos Mezant, ruled out that since cryptocurrency Bitcoin can be used as money to pay for goods or to exchange for traditional currencies such as the US dollar, euro, yen or yuan, Bitcoin is currency or form of money (see Case SEC v. Trendon T. Shavers and Bitcoin Savings and Trust). In September 2016, the District Court Judge of the Southern District of New York, Alison Netan, confirmed that bitcoins are money (Case United States of America V. Anthony R. Murgio).

Contrary to this decision, Miami District Court judge Teresa Poller noted that although Bitcoin may have common and distinctive features with money and can exchange products, it is not an ordinary means of exchange, it is not accepted by all traders or service providers. Also, the judge noted that it is clear that Bitcoin has to go a long way to go until it becomes the equivalent of money (see Case № F14-2923).

Regarding regulation cryptocurrencies at the state level, California was the first state authorized to use cryptocurrency, and the 39th governor of this state, Jerry Brown, signed Act No. 129, which gave Bitcoin and other cryptocurrencies the official status of money. The law allowed any corporation, association, or private person in California to engage in a turnover of money other than the legal funds of the United States.

In Washington DC, the digital currency is a Money Transmission object within the meaning of the Uniform Money ServicesAct Act (Dong He 2016). This means that companies can perform cryptocurrency transfers to a Washington resident only after obtaining the Washington money transfer operator license (Washington Money Transmitter License).

Tax issues in the United States are dealt with by the US Internal Revenue Service. In early 2014, this service published explanations on transactions with cryptocurrencies that are subject to taxation, in particular:

- Wages paid to employees using the virtual currency are taxed on the employee, must be submitted by the employer in the form of $\mathrm{W}-2$ and taxed on the maintenance and accrual of taxes on federal income tax; - The nature of the profit or loss from the sale or exchange of a virtual currency depends on whether the virtual currency is the main asset of the taxpayer;

- A payment made using a virtual currency is subject to informational reporting to the same extent as any other payment made in respect of ownership (IRS 2014).

The tax service, like the SEC, has defined the cryptocurrency as a digital value embodiment, which is distributed in digital form and can be used as a means of accounting, exchange, or accumulation.

At the end of 2017, President Donald Trump signed a new law according to which all agreements with cryptocurrencies will be taxed. That is, operations with cryptocurrencies will be taxed on profit and sales tax.

One of the modern leaders in the regulation of cryptocurrencies is Japan. The need for regulation of cryptocurrencies The Japanese authorities realized after the bankruptcy in 2014 of one of the largest 
crypto-currency exchanges in the world MtGox. After this case, the Japanese authorities set up an investigative commission on what was happening, and also noted that Bitcoin was not a currency, but transactions with subsequent profit should be subject to taxation (Southurst 2014). In connection with the intention of further regulatory legal regulation of this sphere of legal relations, the Commission on the Digital Assets of Japan was established, its activities aimed at protecting the cryptocurrency business, and the feature is that it was created with the support of the state, but at the same time is a non-governmental organization. In essence, the Commission is a body that is self-regulating and created primarily by representatives of the cryptocurrencies industry.

In one of its first instructions, the Digital Assets Commission recommended that companies, when opening exchanges and trading platforms, file a special application for them, and take appropriate measures on financial monitoring issues, in particular complying with the "Know your Customer" policy and measures on security (JADA 2014).

As a result, in 2016, the Japanese parliament passed a law that defined the main areas of legal regulation of the cryptocurrencies sphere:

- Operators of the cryptocurrency exchanges are subject to registration at the Financial Services Agency (FSA);

- The regulator is empowered to carry out stock inspections and, if necessary, may apply administrative measures;

- cryptocurrencies recognized asset-like values.

The Government of Japan in 2017 approved the amendments to the Banking Act and officially recognized Bitcoin as a means of payment (Keirns G 2017).

The issue of taxation of transactions with cryptocurrencies in Japan is carried out in accordance with the general rules - the income received by an individual in cryptocurrencies, is subject to tax on income (IncomeTax); corporate income in the digital currency is taxed on corporate income (CorporateTax); The sale of cryptographic goods is taxed by the Japanese equivalent of VAT (Consumption Tax) (Japan Times 2014).

Ukraine is among the Top 10 countries by number of Bitcoin users. In addition, the largest bitcoin agency Kuna, is operating in the CIS, as well as the use of decentralized blockchain technology in a number of state projects, in particular: e-Auction 3.0, e-Vox, E-Ukraine.

However, today the question of the legal status of cryptocurrencies, their legality, ownership of them, as well as the regulation of operations related to their activities are in the gray zone and are still not resolved. The first attempt made by the state regulators in the person of the National Bank of Ukraine (NBU) was the clarification of this regulator regarding the lawful use of Bitcoin's "virtual currency / cryptocurrency" in Ukraine, in which the regulator recognized Bitcoin as a money surrogate (NBU 2014). The same position was confirmed by the representatives of the State Fiscal Service (DFS) in response to a request from one of the news agencies, in which they stated: "Clarification on the legality of use of the virtual currency / cryptocurrency in Ukraine" was provided by the National Bank of Ukraine on November 10, 2014, according to which the National Bank considers the "virtual currency / cryptocurrency" Bitcoin "as a money surrogate, which has no provision of real value and can not be used by individuals and legal entities on the territory of Ukraine as a means of payment, as contradicts the norms of Ukrainian legislation" (DFS 2014).

At the same time, public authorities, aware of the potential positive and negative aspects of using the blockchain technology in general and cryptocurrencies in particular, have somewhat changed their rhetoric. So in June 2015, a meeting was held on issues of payments of individuals to the public council at the NBU, which included issues of development of the Bitcoin project. And in November 2017, the NBU issued a joint statement with other financial regulators on the status of cryptocurrency in Ukraine, in which they noted that the complex legal nature of the cryptocurrency does not allow them to be recognized either by money, currency or payment instrument of another country, or by currency value , neither electronic money, nor securities, nor a money surrogate (NBU 2017). Moreover, in December 2017, the NBU announced the possibility of issuing e-hryvnias, which will be based on the technology blockchain.

In addition, at the end of 2017, two bills were submitted to the Verkhovna Rada of Ukraine with an attempt to resolve the issue of cryptocurrency at the legislative level, this is the Draft Law No. 7183-1 and the Draft Law No. 7183. From the content of the Draft Law No. 7183 it is seen that its authors qualify cryptocurrency as a program code (a set of characters, numbers and letters) that is the subject of ownership, which can act as a means of payment, information about which is entered and stored in the blockchain system as a unit of the current block system data in the form of data (software code). By cryptocurrency, the general rules apply to the right of private property, and to the cryptocurrencies transactions, the general provisions of the mines contract are applied in accordance with the legislation of 
Ukraine. Thus, cryptocurrency is defined as a commodity, while the NBU acts as a regulator of operations associated with this asset (Article 3).

The authors of the draft Law of Ukraine No. 7183-1 define cryptocurrency as a decentralized numerical value measure that can be expressed in numerical form and functions as a means of exchange, saving of value or accounting unit based on mathematical calculations, is the result of them and has cryptographic protection of accounting. Cryptocurrency for legal purposes is considered a financial asset. Thus, if compared with the functions of money that were discussed above, this bill essentially duplicates their main functions. At the same time, in accordance with Article 6 of this bill, the regulator is a state body that carries out state regulation and supervision of activities in the markets of non-bank financial services. Also, the draft law provides for the organization and operation of institutions that provide services for the exchange, keeping accounts of clients, committing cryptocurrency transactions, etc. Such transactions may be carried out by financial institutions only upon obtaining a license.

However, in our opinion, both draft laws need to be further elaborated, first of all, in view of the fact that it is necessary to amend the other legislative acts in parallel (in particular, to the Civil Code and the Tax Code of Ukraine), by providing the definition and legal status of cryptocurrency as special civil law relations.

\section{Conclusions}

The problem of legal regulation of the circulation of cryptocurrency, generated by the modern globalized world, has a rather complex complex character. At the same time, the regulation of the cryptocurrency business remains the subject of discussions, including at the state level, and the relevant regulatory framework is currently not sufficiently worked out, so that every occurrence of cryptocurrency relations should be considered individually.

In view of the above, answering the question of what from the economic and legal point of view is the cryptocurrency and whether this term is appropriate at all? In our opinion, it is possible to partly agree with the definition of $\mathrm{M}$. Abramovich, that under cryptocurrency is understood as the type of digital currency emission, and accounting of which require the use of asymmetric encryption and cryptographic methods of protection. After all, today cryptocurrency meets all the necessary functions, which are put forward for money: they can be a measure of value, a means of circulation of goods or services, a means of accumulation and a means of payment. However, in addition to the above-mentioned functions, cryptocurrencies may also act as securities and as goods for barter exchange, which greatly complicates their nature.

In this way, we offer the author's definition of cryptocurrency. Cryptocurrency is a digital value that can be used as a means of accounting, exchange, payment and accumulation, or to act as an asset, the issue and accounting of which require the use of asymmetric encryption and cryptographic methods of protection.

Given that cryptocurrency can act as a means of accumulation and exchange and are used by investors to generate potential returns, and also given that, in some cases, cryptocurrency may have a property of securities (so-called Equity Tokens), there is a need for licensing companies that provide services on the transfer, sale or exchange of cryptocurrencies, the introduction of procedures for the identification and verification of customers. In our opinion, such measures, on the one hand, will significantly increase the area of responsibility of companies to investors for the storage of their assets, and, on the other hand, significantly reduce the possibility of using cybercriminals to legalize the proceeds of crime and use them to finance terrorism.

As regards the question of taxation of cryptocurrency transactions, it should be noted that tax levies are the sovereign right of each individual state and therefore, in our opinion, should be dealt with accordingly in each country separately, depending on one or another status that will be granted to cryptocurrencies in a particular jurisdiction. However, on the basis of the definition we have previously proposed, as well as the nature of the cryptocurrency as such, we agree with the Court of Justice of the European Union that operations with cryptocurrencies should not be subject to the VAT tax. After all, transactions with this instrument are more likely to be related to currency transactions, given the functions of cryptocurrencies. So should such transactions be taxed and what exactly? So, of course, like all business transactions they should be taxed, but because of their essence, we believe that cryptocurrency transactions should be taxed on corporate profit tax, or on the income tax of individuals, as well as on capital gains tax (Azer Dilanchiev, Gryshova Inna, Rogach Svetlana, Diachenko Oleksii, Batrakova Tetyana, Shabatura Tatyana, 2020)

So regulation of cryptocurrencies and their partial legalization will inevitably come, as the blockchain technology is quite resistant to external opposition. At the same time for legal regulation, there are quite a lot of "border areas", on which blockchain interacts with objects of the real world. 
As we have noted today, state regulation of cryptocurrencies takes place in four main areas:

- definition of the legal status of cryptocurrencies is necessary, since today they do not correspond to any of the objects of civil-law relations;

- Establishing the place of cryptocurrency in the system of settlements among economic operators and the need for taxation of operations related to cryptocurrency;

- the problem of licensing transactions with cryptocurrency;

- Definition of state bodies that have control over cryptocurrencies in order to prevent their use in illegal activities, in particular terrorist financing, and laundering of proceeds from crime.

In addition, effective mechanisms of international co-operation should be created, concerning legal liability for violations of an economic nature, in particular financial fraud, as was the case with the bankruptcy of the MtGox Exchange and the closure of the BTC-E Exchange.

However, a significant public interest in the problem results in the need to find an adequate mechanism for legal regulation, since existing self-regulation methods do not protect property rights and legitimate interests.

\section{References}

Abramowicz, Michael B., Cryptocurrency-Based Law (August 28, 2015). GWU Law School Public Law Research Paper 2015-9; GWU Legal Studies Research Paper No. 2015-9. Available at SSRN: https://ssrn.com/abstract=2573788 or http://dx.doi.org/10.2139/ssrn.2573788 Accessed 30 Oct 2018 Action Plan for anti-money laundering and counter-terrorist finance (2016). https://goo.gl/ysef9R Accessed 29 Oct 2018

Barrdear J. and Kumhof M (2016) The macroeconomics of central bank issued digital currencies. https://goo.gl/aagyk2 Accessed 29 Oct 2018
Bryan
A. Garner
(2009)
Black's Law Dictionary,
9-th
Edition/

https://thelawdictionary.org/letter/m/page/78/ Accessed 29 Oct 2018

Cambridge Dictionary. https://goo.gl/zv7o5W Accessed 29 Oct 2018

Case № 4 13-cv-416 (2013) Securities and Exchange Commission V. Trendon T. Shavers and Bitcoin Savings and Trust https://goo.gl/5x5fo6 Accessed 29 0ct 2018

Case № 13 crm 368 (2013) U.S. v. Liberty Reserve https://goo.gl/LGnocY Accessed 30 Oct 2018

Case № 15-cr-769 (AJN) (2016) United States of America v. Anthony R. Murgio, et al, https://cdn.arstechnica.net/wp-content/uploads/2016/09/murgio-order.pdf Accessed 30 Oct 2018

Case № F14-2923 (2016) State of Florida v. Espinoza https://goo.gl/w8wxZ5 Accessed 30 Oct 2018

DFS (2014) to determine the status of Bitcoin. https://ua.interfax.com/news/general/445057.html Accessed 31 Oct 2018

Dong He \& Karl F Habermeier \& Ross B Leckow \& Vikram Haksar \& Yasmin Almeida \& Mikari Kashima \& Nadim Kyriakos-Saad \& Hiroko Oura \& Tahsin Saadi Sedik \& Natalia Stetsenko \& Concha Verdugo Yepes, 2016. "Virtual Currencies and Beyond; Initial Considerations," IMF Staff Discussion Notes 16/3, International Monetary Fund. https://www.imf.org/external/pubs/ft/sdn/2016/sdn 1603.pdf Accessed 27 Oct 2018

Dubicinsky VV (2008) Modern Dictionary of the Ukrainian Language (Kyiv, 2008), 1008 p.

European Central Bank (2016) Opinion of the European Central Bank CON/2016/https://www.ecb.europa.eu/ecb/legal/pdf/en_con_2016_49_f_sign.pdf Accessed 31 Oct 2018 European Commission (2016) Questions and Answers: Action Plan to strengthen the fight against terrorist financing https://goo.gl/kuuCre Accessed 31 Oct 2018

European Court of Justice (2015) Case C-264/14 David Hedqvist v. The Swedish Government https://goo.gl/sUisfo Accessed 30 Oct 2018

Japan Authority of Digital Assets (2014) Summary of Guidelines for JADA. https://goo.gl/CbBh5p Accessed 30 Oct 2018

Karpenko $O$ (2017) In Ukraine for the first time officially sold an apartment for cryptocurrency. https://ain.ua/2017/09/26/kvartiru-za-ethereum. Accessed 31 Oct 2018

Keirns G (2017) Japan's Bitcoin Law Goes Into Effect Tomorrow https://www.coindesk.com/japanbitcoin-law-effect-tomorrow/ Accessed 30 Oct 2018

Kshemkalyani A (2008) Distributed Computing. Principles, Algorithms And Systems (Cambridge : University $\quad$ Press, 2008$), \quad 756 \quad$ p https://eclass.uoa.gr/modules/document/file.php/D245/2015/DistrComp.pdf Accessed 29 Oct 2018

Gryshova, I.I., Mityay, O.V., Kuzhel, V.V.. (2015) Evaluation of financial potential development factors in agricultural production . Actual Problems of Economics. № 10(172). - C.169-172.7

MacDonald T.J., Allen D.W.E., Potts J. (2016) Blockchains and the Boundaries of Self-Organized Economies: Predictions for the Future of Banking. In: Tasca P., Aste T., Pelizzon L., Perony N. (eds) Banking Beyond 
Banks and Money. New Economic Windows. Springer, Cham. Doi: https://doi.org/10.1007/978-3-31942448-4 14

Mills, David, Kathy Wang, Brendan Malone, Anjana Ravi, Jeff Marquardt, Clinton Chen, Anton Badev, Timothy Brezinski, Linda Fahy, Kimberley Liao, Vanessa Kargenian, Max Ellithorpe, Wendy Ng, and Maria Baird (2016). "Distributed ledger technology in payments, clearing, and settlement," Finance and Economics Discussion Series 2016-095. Washington: Board of Governors of the Federal Reserve System, https://doi.org/10.17016/FEDS.2016.095. Accessed 27 Oct 2018.

NBU 2014 Clarification on the lawfulness of use of "virtual currency / cryptocurrency" in Ukraine "Bitcoin // National Bank of Ukraine. https://goo.gl/Lzbxa2 Accessed 31 Oct 2018

NBU 2017 Joint statement of financial regulators concerning the status of cryptocurrencies in Ukraine. https://bank.gov.ua/control/uk/publish/article?art id=59735329 Accessed 31 Oct 2018

Shcherbak S (2014) How Should Bitcoin be Regulated? Scientific works of the European Journal Of Legal Studies 7(1):42-83/ https://goo.gl/hzmmT2 Accessed 27 Oct 2018

Southurst J (2014) Japanese Government Says Bitcoin 'Not a Currency', Forms Investigation Committee https://www.coindesk.com/japanese-government-says-bitcoin-currency-forms-investigation-

committee/ Accessed 30 Oct 2018

SWAN, M. (2015). Blockchain: blueprint for a new economy. Beijing, O'Reilly. 152p.

The Commonwealth Working Group Report (2015) https://goo.gl/w38sQs Accessed 27 Oct 2018

The Internal Revenue Service (2014) IRS Virtual Currency Guidance https://www.irs.gov/newsroom/irsvirtual-currency-guidance Accessed 29 Oct 2018

The Japan Times (2014) Regulating bitcoins https://goo.gl/Wy3x3a Accessed 1 Nov 2018

Vasylchak, S., Kunytska-Ilyash, M., \& Dubyna, M. (2017). Using of cryptocurrency in the modern economic systems of Ukraine: prospects and risks. Scientific Messenger of LNU of Veterinary Medicine and Biotechnologies, 19(76), 19-25. https://doi.org/10.15421/nvlvet7604

Washington State Department of Financial Institutions (2014) Virtual Currency Regulation https://goo.gl/hZktFv Accessed 29 Oct 2018

Electronic resource (2018) https://cointelegraph.com/news/bitcoin-is-epidemic-of-enthusiasm-saysnobel-prize-winner-robert-shiller Accessed 27 Oct 2018

Electronic resource (2017) https://www.dailymail.co.uk/sciencetech/article-5000260/Bitcoinpredicted-Milton-Friedman-18-years-ago.html Accessed 27 Oct 2018

Electronic resource (2015) https://news.bitcoin.com/economics-nobel-winner-angus-deaton-case-forbitcoin/ Accessed 27 Oct 2018

Gryshova, I.; Demchuk, N.; Koshkalda, I.; Stebliuk, N.; Volosova, N. Strategic Imperatives of Managing the Sustainable Innovative Development of the Market of Educational Services in the Higher Education System. Sustainability 2019, 11, 7253.

Gryshova, I.; Shabatura, T.; Girdzijauskas, S.; Streimikiene, D.; Ciegis, R.; Griesiene, I. The Paradox of Value and Economic Bubbles: New Insights for Sustainable Economic Development. Sustainability 2019, 11, 6888

Dr. Tetiana Tielkiniena, Gryshova Inna, Shabatura Tatyana, Nehodenko Viktoriia, Didur Hanna, Shevchenko Alisa. LOBBY LEGALIZATION - LEGAL INSTRUMENT FOR ENSURING STATE SUBSIDIES TO LEADERS OF AGRICULTURAL PRODUCERS . JCR. 2020; 7(4): 1679-1683. doi:10.31838/jcr.07.04.274

Azer Dilanchiev, Gryshova Inna, Rogach Svetlana, Diachenko Oleksii, Batrakova Tetyana, Shabatura Tatyana. REMITTANCE LEVELS AND ENTREPRENEURIAL ACTIVITY IN POSTSOVIET COUNTRIES . JCR. 2020; 7(4): 1655-1663. doi:10.31838/jcr.07.04.271 